\title{
Dual Receptor Recognizing Cell Penetrating Peptide for Selective Targeting, Efficient Intratumoral Diffusion and Synthesized Anti-Glioma Therapy
}

\author{
Yayuan $\mathrm{Liu}^{1}$, Ling $\mathrm{Mei}^{1}$, Chaoqun $\mathrm{Xu}^{2}$, Qianwen $\mathrm{Yu}^{1}$, Kairong Shi ${ }^{1}$, Li Zhang ${ }^{1}$, Yang Wang ${ }^{1}$, Qianyu \\ Zhang ${ }^{1}$, Huile Gao ${ }^{1}$, Zhirong Zhang1, Qin $\mathrm{He}^{1,}{ }^{\bowtie}$ \\ 1. Key Laboratory of Drug Targeting and Drug Delivery Systems, West China School of Pharmacy, Sichuan University, No. 17, Block 3, Southern Renmin \\ Road, Chengdu 610041, China \\ 2. Sichuan Academy of Chinese Medicine Sciences, No. 51, Block 4, Southern Renmin Road, Chengdu 610041, China \\ $\square$ Corresponding author: Tel. / fax: +86 28 85502532. E-mail addresses: qinhe@scu.edu.cn (Q. He).
}

(1) Ivyspring International Publisher. Reproduction is permitted for personal, noncommercial use, provided that the article is in whole, unmodified, and properly cited. See http://ivyspring.com/terms for terms and conditions.

Received: 2015.08.11; Accepted: 2015.10.01; Published: 2016.01.01

\begin{abstract}
Cell penetrating peptides (CPPs) were widely used for drug delivery to tumor. However, the nonselective in vivo penetration greatly limited the application of CPPs-mediated drug delivery systems. And the treatment of malignant tumors is usually followed by poor prognosis and relapse due to the existence of extravascular core regions of tumor. Thus it is important to endue selective targeting and stronger intratumoral diffusion abilities to CPPs. In this study, an RGD reverse sequence dGR was conjugated to a CPP octa-arginine to form a CendR (R/KXXR/K) motif contained tandem peptide R8-dGR (RRRRRRRRdGR) which could bind to both integrin $\alpha_{v} \beta_{3}$ and neuropilin-1 receptors. The dual receptor recognizing peptide R8-dGR displayed increased cellular uptake and efficient penetration ability into glioma spheroids in vitro. The following in vivo studies indicated the active targeting and intratumoral diffusion capabilities of R8-dGR modified liposomes. When paclitaxel was loaded in the liposomes, PTX-R8-dGR-Lip induced the strongest anti-proliferation effect on both tumor cells and cancer stem cells, and inhibited the formation of vasculogenic mimicry channels in vitro. Finally, the R8-dGR liposomal drug delivery system prolonged the medium survival time of intracranial $\mathrm{C} 6$ bearing mice by 2.1 -fold compared to the untreated group, and achieved an exhaustive anti-glioma therapy including anti-tumor cells, anti-vasculogenic mimicry and anti-brain cancer stem cells. To sum up, all the results demonstrated that R8-dGR was an ideal dual receptor recognizing CPP with selective glioma targeting and efficient intratumoral diffusion, which could be further used to equip drug delivery system for effective glioma therapy.
\end{abstract}

Key words: Cell penetrating peptides, Tumor penetration, C-end Rule, Glioma targeting, Anti-glioma

\section{Introduction}

Cell penetrating peptides (CPPs) are a class of diverse short peptides which can break through various bio-barriers including blood-brain barrier (BBB), intestine wall, retina and neurons[1, 2]. In recent decade, CPPs were widely used for tumor delivery of nano drug carriers due to their ability of overwhelming cell penetration and internalization[3-5]. Nevertheless, the application of CPP-mediated drug carriers was greatly limited because of the nonselectivity of CPPs in vivo[2]. Besides, it is difficult for nanocarriers to deliver deep into the hypoxic and necrotic regions of solid tumors due to the elevated interstitial fluid pressure (IFP), abnormal vasculature and relative high cell density[6-9]. Although CPPs would benefit intratumoral diffusion of drug delivery systems in some degree, the penetration efficiency into the core 
areas distant from the vascular bed was still limited and needed to be further improved. And this improvement would significantly enhance the anti-tumor therapeutic effect[10]. Therefore, the structural modification of CPPs focused on enhancing the selective targeting and intratumoral penetrating abilities is necessary.

Erkki Ruoslahti's group identified that an exposed $\mathrm{R} / \mathrm{KXXR} / \mathrm{K} \mathrm{C}$-terminal sequence of peptide could specifically recognize a cell surface receptor neuropilin-1 (NRP-1) which plays an important role in angiogenesis and regulation of vascular permeability[11]. NRP-1 was found overexpressed on both endothelial cells and tumor cells $[12,13]$, thus this kind of C-terminal motif could efficiently mediate cell, vascular and tissue penetration by binding to NRP-1[11]. This phenomenon was termed C-end Rule (CendR) and proved in many researches[14-17]. In the previous study, our group had reported that a tandem peptide by combination of R8 and c(RGDfK) could overcome the non-selective property of CPPs, thus achieve a successful BBB transporting and glioma targeting effect[18]. Based on this and in order to further enhance the glioma tissue penetrating ability, we designed another dual receptor recognizing cell penetrating peptide herein with a sequence of RRRRRRRRdGR (R8-dGR, lower case letter represents D-amino acid residue). By connecting an RGD reverse sequence $\mathrm{dGR}$ to a $\mathrm{CPP}$ octa-arginine, this peptide was endued with selective targeting property by recognizing both integrin $\alpha_{v} \beta_{3}$ and NRP-1 receptors, and could undergo a CendR based intratumoral penetrating process. This is the first time to report one CPP-based peptide which could recognize two kinds

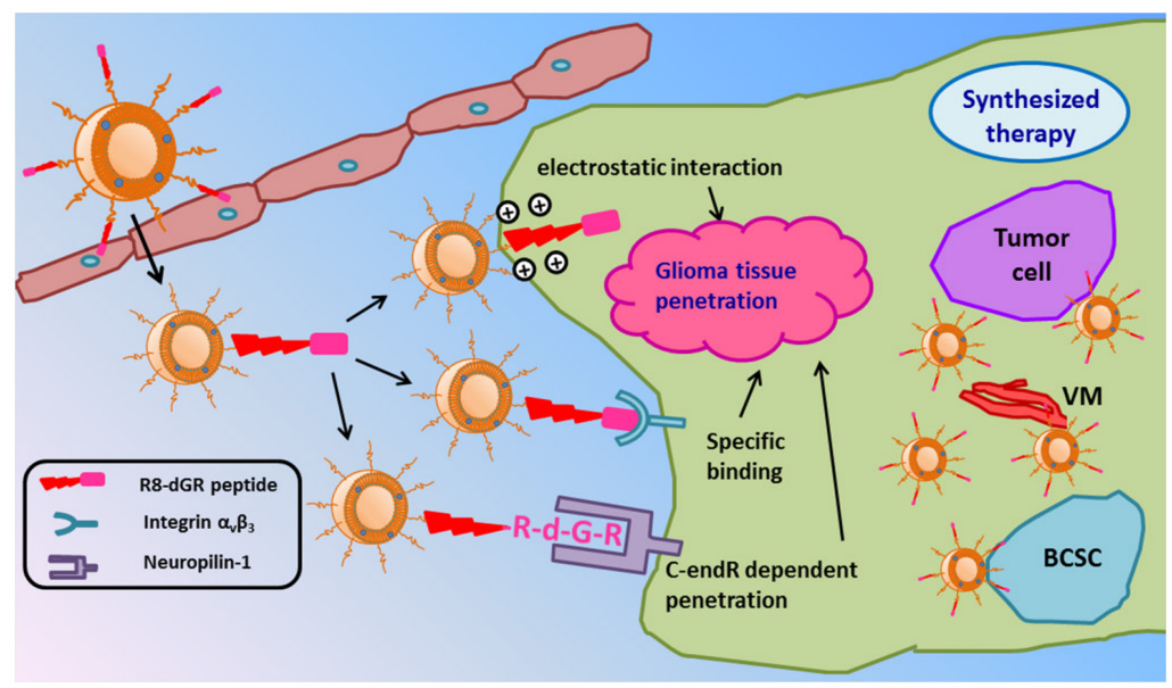

Fig. 1. Schematic illustration of PTX-R8-dGR-Lip. After transporting across the BBB and accumulating in glioma foci, liposomes could achieve an efficient synergetic glioma tissue penetration through three pathways and accomplish a synthesized anti-glioma therapy by combined treatment of tumor cells, VM and BCSCs. of receptors on tumor cells, and the tumor targeting and tissue penetrating capabilities could both be enhanced.

Recent researches proved that aggressive tumors like malignant glioma was highly correlated with the formation of vasculogenic mimicry (VM) and brain cancer stem cells (BCSCs)[19-22]. VM is non-endothelial tumor cell-lined microvascular channel which could transport nutrients independent of endothelial blood vessels[23]. Researchers suggested that VM provided an alternative vascularization pathway to keep tumor cells nourished in hypoxic and ischemic microenvironment[24]. Meanwhile, during the tumorigenesis of glioma, a few subpopulations of glioma cancer cells expressing CD133 are enriched to form cancer stem cells and exhibit greater tumorigenic potential than normal cancer cells[25]. BCSCs are commonly tolerated to chemotherapeutics and possess the capabilities of self-renewal and proliferation, which inevitably lead to the relapse of glioma[26]. Therefore, the synthesized anti-glioma effect with combined treatment of tumor cells, VM and BCSCs is important.

In this study, we hypothesized paclitaxel (PTX) loaded R8-dGR modified liposomes (PTX-R8-dGR-Lip) as potential anti-glioma drug delivery systems. As illustrated in Fig. 1, PTX-R8-dGR-Lip could transport across the BBB through integrin-binding and CPP mediated penetrating. After accumulated in the glioma foci, R8-dGR could induce an efficient glioma tissue penetrating process via the synergetic effect of three pathways including electrostatic interaction, specific binding with integrin $\operatorname{av} \beta 3$ and CendR dependent penetration. Therefore, PTX-loaded liposomes could be delivered to the inner region of glioma and exhibit a synthesized anti-glioma therapeutic effect by combined treatment of tumor cells, vasculogenic mimicry and brain cancer stem cells. We investigated the integrin $\alpha_{v} \beta_{3}$ and NRP-1 recognizing, glioma spheroids penetrating and $\mathrm{BBB}$ model transporting abilities of R8-dGR in vitro, studied the glioma targeting properties of modified liposomes in vivo, and carried out a synthesized anti-glioma evaluation by investigating the inhibition effect of different PTX-Lip on C6 cells, C6 VM channels and C6 stem cells both in vitro and in vivo. 


\section{Materials and methods}

\section{Materials}

R8-dGR, R8-RGD and R8-EGR peptide with an N-terminal cysteine (Cys-RRRRRRRRdGR, Cys-RRRRRRRRRGD and Cys-RRRRRRRREGR) were synthesized according to the standard solid phase peptide synthesis by Chinapeptides Co. Ltd. (Shanghai, China). R8 peptide with an N-terminal cysteine (Cys-RRRRRRRR) was synthesized according to the standard solid phase peptide synthesis by Chengdu Kai Jie Bio-pharmaceutical Co. Ltd. (Chengdu, China). Soybean phospholipids (SPC) were purchased from Shanghai Taiwei Chemical Company (Shanghai, China). Cholesterol was purchased from Chengdu Kelong Chemical Company (Chengdu, China). 1, 2-dioleoyl-sn-glycero-3-phosphoethanolamine-N-(car boxyfluorescein) (CFPE), were obtained from Avanti Polar Lipids (USA). DSPE-PEG 2000 and DSPE-PEG $2000-$ Mal were purchased from Shanghai Advanced Vehicle Technology (AVT) L.T.D. Company (Shanghai, China). Paclitaxel was purchased from AP Pharmaceutical Co. Ltd. (Chongqing, China). The recombinant mouse integrin $\alpha_{v} \beta_{3}$ was purchased from R\&D systems (U.S.A). Rabbit anti-mouse $\beta_{3}$ integrin primary antibodies were purchased from Epitomics, Abcam (California, USA). Rabbit anti-Neuropilin 1, anti-CD133 anti-GAPDH and anti-ZO-1 antibodies were purchased from Boster (China). Horseradish peroxidase (HRP) -labeled goat anti-rabbit secondary antibodies was purchased from ZSGB-BIO (Beijing, China). 1, 10-dioctadecyl- 3, 3, 30, 30-tetramethylindodicarbocyanine,

4-chlorobenzenesulfonate salt (DiD) were purchased from Biotium (USA). Annexin V-FITC/PI apoptosis detection kit was purchased from KeyGEN Biotech (China). BD Matrigel ${ }^{\mathrm{TM}}$ Basement Membrane Matrix was purchased from BD Biosciences (Franklin Lakes, NJ). Millicell Hanging Cell Culture Inserts were purchased from Millipore (USA). The other chemicals were obtained from commercial sources.

Balb/c mice were purchased from West China animal center of Sichuan University (Sichuan, China). All animal experiments were approved by the Experiment Animal Administrative Committee of Sichuan University.

\section{Synthesis of different materials}

Peptide conjugated DSPE-PEG 2000 materials (DSPE-PEG $2000-R 8-d G R, \quad$ DSPE-PEG $2000-R 8-R G D$, DSPE-PEG $2000-R 8-E G R$ and DSPE-PEG $2000-R 8)$ were synthesized through Michael addition reaction. Briefly, DSPE-PEG $2000-\mathrm{Mal}$ and Cys-R8-dGR (or Cys-R8-RGD, Cys-R8-EGR, Cys-R8) were dissolved with a molar ratio of 1: 1.5 in chloroform/methanol $(\mathrm{v} / \mathrm{v}=2: 1)$ containing triethylamine as a catalyst. The mixture was then allowed to react for $24 \mathrm{~h}$ in darkness under room temperature. After the disappearance of DSPE-PEG $_{2000}$-Mal was confirmed by thin layer chromatography, the organic solvent was evaporated by rotary evaporation and the residue was redissolved by chloroform. The solution was then filtered for purification and the filtrate was evaporated again to obtain the production. All the DSPE-PEG 2000 materials were stored under $-20^{\circ} \mathrm{C}$ until used. The synthesis of DSPE-PEG ${ }_{2000}-R 8-d G R$, DSPE-PEG $2000-R 8-R G D$ and DSPE-PEG $2000-R 8$ was confirmed by mass spectrometry (autoflex III smartbeam, Bruker, USA) while that of DSPE-PEG $2000-R 8$-EGR was detected by MS (Q-TOF Premier, Waters, USA). All the DSPE-PEG ${ }_{2000}$-peptide conjugates were analyzed by HPLC (Agilent, USA). The mobile phase was a 30:70 $(\mathrm{V} / \mathrm{V})$ mixture of acetonitrile and water containing $0.1 \%$ trifluoroacetic acid. The samples were detected at $220 \mathrm{~nm}$.

\section{Preparation and characterization of liposomes}

All the liposomes were prepared by thin film hydration method. In brief, SPC, cholesterol and DSPE-PEG $_{2000}$ (molar ratio $=62: 33: 5$ ) were dissolved in chloroform. Then the organic solvent was evaporated by rotary evaporation. The formed lipid film was hydrated in phosphate buffered saline ( $\mathrm{pH}$ 7.4) for 20 min under $37^{\circ} \mathrm{C}$. Then the solution was intermittently sonicated by a probe sonicator at $80 \mathrm{~W}$ for 80 $s$ to form PEGylated liposomes (PEG-Lip). R8-dGR modified liposomes (R8-dGR-Lip), R8-RGD modified liposomes (R8-RGD-Lip), R8-EGR modified liposomes (R8-EGR-Lip) and R8 modified liposomes (R8-Lip) were prepared by a similar method with $0.8 \%$ of DSPE-PEG 2000 in PEG-Lip being replaced by equal amounts of DSPE-PEG $2000-R 8-d G R$, DSPE-PEG $2000-R 8-R G D$, DSPE-PEG $2000-R 8-E G R$ and DSPE-PEG $2000-R 8$, respectively. PTX-loaded liposomes (PTX-Lip), CFPE-labeled liposomes and DiD-loaded liposomes were prepared with appropriate amount of PTX, CFPE or DiD added to the lipid solution prior to the evaporation respectively.

The entrapment efficiency of PTX was determined by HPLC (Agilent, USA). Malvern Zetasizer Nano ZS90 (Malvern Instruments Ltd., UK) was used to determine the mean size and zeta potential of different groups of liposomes. Serum stability of liposomes was evaluated by monitoring the turbidity variations of liposomes incubated with FBS. Liposomes were mixed with equal volume of FBS and then incubated under $37^{\circ} \mathrm{C}$ with gentle oscillating for $48 \mathrm{~h}$. At predetermined time points, the transmittance of the mixture was measured by a microplate reader (Thermo Scientific Varioskan Flash, USA) at $750 \mathrm{~nm}$. 
In vitro drug release study was performed by a dialysis method using PBS ( $\mathrm{pH} 7.4$ ) containing $0.1 \%$ Tween $80(\mathrm{v} / \mathrm{v})$ as the release media. $0.5 \mathrm{~mL}$ PTX-loaded liposomes or free PTX were placed into cellulose acetate dialysis tubes (MWCO 8-14 kDa) and immersed in $50 \mathrm{~mL}$ release medium, followed by gently shaking under $37^{\circ} \mathrm{C}$. Then $0.1 \mathrm{~mL}$ release media was sampled and replaced with equal volume of fresh release media at predetermined time points. The amount of released PTX was analyzed by HPLC.

Surface plasmon resonance (SPR) technology was performed to evaluate the interaction efficiency between liposomes and integrin. A biacore T200 instrument (Biacore T200, GE Healthcare) was used here. Integrin $\alpha_{v} \beta_{3}$ was linked on CM5 sensor chips by amine coupling. After the baseline was stable, different liposomes were injected over the sensor chips for $30 \mathrm{~s}$ at a flow rate of $10 \mu \mathrm{L} / \mathrm{min}$. The response signals were then recorded and analyzed. Before each injection, the phosphate buffer was used to wash the samples off the sensor chip.

\section{Cell culture}

C6 cells (murine glioma cells), bEnd. 3 cells (murine brain endothelial cells) and Hela cells (human cervical carcinoma cells) were cultured in DMEM medium (Gibco) supplement with 10\% fetal bovine serum (FBS), $100 \mathrm{U} / \mathrm{mL}$ penicillin and $100 \mu \mathrm{g} / \mathrm{mL}$ streptomycin at $37{ }^{\circ} \mathrm{C}$ in a humidified $5 \% \mathrm{CO}_{2}$ atmosphere.

\section{Receptor expression level}

The expression level of NRP- 1 and integrin $\beta_{3}$ on C6 cells, bEnd. 3 cells and Hela cells were measured using western blot studies. The total protein samples of different kinds of cells were extracted, separated on $10 \%$ SDS-PAGE and transferred to polyvinylidene difluoride membranes. The membranes were incubated with Rabbit anti-Neuropilin-1, anti- integrin $\beta_{3}$ or anti-GAPDH primary antibodies. All the membranes were then incubated with HRP-labeled goat anti-rabbit secondary antibodies and monitored by Immobilon Western HRP Substrate (Millipore, USA) on a Bio-Rad ChemiDoc MP System (Bio-Rad Laboratories, USA).

\section{Cellular uptake study}

The liposomal cellular uptake was evaluated on C6, bEnd.3 and Hela cells. For quantitative analysis, all kinds of cells were plated in 6-well plates at a density of $5 \times 10^{5}$ cells per well. After incubation for $24 \mathrm{~h}$, different CFPE-labeled liposomes were added into the plates for $4 \mathrm{~h}$ incubation. Then the cells were washed twice with cold PBS, trypsinized, resuspended in 0.5 $\mathrm{mL}$ PBS and finally analyzed by a flow cytometer (Cytomics FC 500, Beckman Coulter, USA).
As for the qualitative analysis, $1 \times 10^{5}$ cells were seeded on gelatin coated cover slip in 6-well plates and allowed to culture for $24 \mathrm{~h}$. After another $4 \mathrm{~h}$ incubation with CFPE-labeled liposomes, cells were washed twice with cold PBS, fixed with $4 \%$ paraformaldehyde for $30 \mathrm{~min}$, and stained with DAPI for 5 min. Finally, the cells were imaged using a confocal laser scanning microscopy (FV1000, Olympus, USA).

\section{C6 tumor spheroid uptake}

C6 tumor spheroids in vitro were cultured as follows. Briefly, $2 \%(\mathrm{w} / \mathrm{v})$ low melting point agarose was added into a 96-well plate. $5 \times 10^{3} \mathrm{C} 6$ cells were seeded on the agarose coated plate and incubated till uniform spheroids formed. CFPE-labeled liposomes were added for $4 \mathrm{~h}$ spheroids uptake, and then the spheroids were washed twice with cold PBS and imaged with a confocal microscopy (FV1000, Olympus, USA).

\section{BBB model study in vitro}

BBB model was established using Millicell Hanging Cell Culture Inserts. In brief, $1 \times 10^{6} \mathrm{bEnd} .3$ cells were plated into a cell culture insert and cultured for about 7 days. BEnd. 3 monolayer with a transendothelial electric resistance (TEER) over $200 \Omega$ could be used for further experiments. Then the cell culture inserts with bEnd. 3 monolayer were transferred onto another 6-well plate containing pre-plated C6 cells and the whole system was co-cultured for another 24 h. CFPE-labeled liposomes were added into the donor chamber. After $8 \mathrm{~h}$ incubation, both bEnd. 3 cells and C6 cells were collected and analyzed with a flow cytometer (Cytomics FC 500, Beckman Coulter, USA). On the other hand, C6 cells from the acceptor chamber were also imaged with a confocal microscopy (FV1000, Olympus, USA) for qualitative evaluation.

To identify the tight junction formed on the bEnd.3 monolayer, an immunofluorescence study was carried out. The bEnd.3 monolayer was incubated with Rabbit anti-mouse ZO-1 antibodies and followed by staining with FITC-labeled Goat anti-Rabbit secondary antibodies. Then the monolayer was washed with cold PBS, fixed and stained with DAPI, and finally imaged using a confocal microscopy (FV1000, Olympus, USA).

\section{Cytotoxicity and apoptosis study in vitro}

C6 cells were plated in a 96-well plate at a density of $2 \times 10^{3}$ cells per well for MTT assay. After cultured for $24 \mathrm{~h}$, PTX-loaded liposomal formulations were added at pre-determined PTX concentrations for another $24 \mathrm{~h}$ incubation. $20 \mu \mathrm{L}$ MTT solution (5 $\mathrm{mg} / \mathrm{mL}$ ) was then added in each well for $4 \mathrm{~h}$ incubation. Finally, the medium was removed and the cells were dissolved in $150 \mu \mathrm{L}$ dimethyl sulfoxide. The ab- 
sorbance of the solution was determined at $490 \mathrm{~nm}$ with a microplate reader (Thermo Scientific Varioskan Flash, USA).

Annexin V-FITC/PI dual staining was used for apoptosis study. C6 cells were treated with different groups of PTX-Lip or free PTX at a PTX concentration of $1 \mu \mathrm{g} / \mathrm{mL}$. After $24 \mathrm{~h}$ incubation, cells were collected, washed twice with cold PBS, suspended in $0.5 \mathrm{~mL}$ binding buffer and dual stained by Annexin V-FITC/PI. Finally, C6 cells were measured by a flow cytometer (Cytomics FC 500, Beckman Coulter, USA).

\section{Destruction of Vasculogenic Mimicry channels}

In vitro VM formation was tested using a Matrigel-based tube formation assay. $150 \mu \mathrm{L}$ Matrigel was plated into 24-well plates and allowed to incubate for $1 \mathrm{~h}$ under $37^{\circ} \mathrm{C}$. C6 cells were resuspended with serum free culture medium and seeded on Matrigel at a density of $2.5 \times 10^{5}$ cells per well. Different PTX-Lip or free PTX were added into the wells immediately to form a $1 \mu \mathrm{g} / \mathrm{mL}$ PTX final concentration. After incubation for $6 \mathrm{~h}$ and $24 \mathrm{~h}$, the plates were observed to monitor the formation of VM channels and photographed with Carl Zeiss 40CFL Axiovert 40 inverted microscopy (Germany).

\section{Cytotoxicity study on brain cancer stem cells}

BCSCs were cultured following a previously described protocol. Briefly, C6 glioma cells were cultured with serum free DMEM culture medium containing 2\% B27 supplement, $20 \mathrm{ng} / \mathrm{mL}$ basic fibroblast growth factor and $20 \mathrm{ng} / \mathrm{mL}$ epidermal growth factor. After continuous culture for 3 weeks, brain cancer stem cell tumorspheres were imaged with Carl Zeiss 40CFL Axiovert 40 inverted microscopy (Germany). Western blot was used for the detection of CD133 expression level. Total protein of C6 cells and C6 stem cells were resolved on 10\% SDS-PAGE and transferred to polyvinylidene difluoride membranes. The membranes were incubated with Rabbit anti-CD133 primary antibodies, followed by incubation with HRP-labeled goat anti-rabbit secondary antibodies and finally detected by Immobilon Western HRP Substrate (Millipore, USA) on a Bio-Rad ChemiDoc MP System (Bio-Rad Laboratories, USA).

The induced C6 stem cells were suspended with serum containing culture medium again and seeded in 96-well plates at a density of $2 \times 10^{3}$ cells per well. Cells were then treated as described above for MTT assay.

\section{In vivo imaging study}

Balb/c mice were anesthetized and set on a stereotaxic apparatus. $\mathrm{C} 6$ glioma cells $\left(1 \times 10^{6}\right.$ cells $/ 5 \mu \mathrm{L}$ in PBS) were slowly injected into the right brain of each mouse. After raised for about 10 days, glioma bearing mice were injected with DiD-loaded liposomes. Mice were imaged with IVI Spectrum system (Caliper, Hopkington, MA, USA) at $1 \mathrm{~h}, 4 \mathrm{~h}, 8 \mathrm{~h}$ and 24 $\mathrm{h}$ after injection. Then the mice were sacrificed after heart perfusion and main organs including brains, hearts, livers, spleens, lungs and kidneys were collected. All the organs were imaged with IVI Spectrum system (Caliper, Hopkington, MA, USA). For liposomal glioma distribution, brains of the $24 \mathrm{~h}$ post-injection mice were fixed in $4 \%$ paraformaldehyde, dehydrated in $10 \%$ and $30 \%$ sucrose solution, and sectioned at the glioma domain at a thickness of $10 \mu \mathrm{m}$. The sections were then incubated with DAPI for nuclei staining and imaged by a confocal microscopy (FV1000, Olympus, USA).

\section{Anti-glioma efficacy}

C6 glioma bearing mice were randomly divided into 7 groups $(\mathrm{n}=10)$ as follows: Saline, free PTX, PTX-PEG-Lip, PTX-R8-Lip, PTX-R8-RGD-Lip, PTX-R8-EGR-Lip and PTX-R8-dGR-Lip. At 4, 6, 8, 10, 12 and 14 days after glioma inoculation, mice were intravenously injected with corresponding PTX formulations at a PTX dosage of $3 \mathrm{mg} / \mathrm{kg}$. Saline group was used as negative control. On the $15^{\text {th }}$ day of glioma implantation, one mouse of each group was chosen and sacrificed. All the seven brains were collected for paraffin sections. Hematoxylin and eosin (HE) staining was performed for tumor tissue observation. CD34 and periodic acid-Schiff (PAS) dual staining was used for VM monitoring, and CD133 based immunoperoxidase method was carried out for BCSCs observation. The survival time of the rest of the mice was recorded and Kaplan-Meier survival curves were plotted for each group.

\section{Statistical analysis}

All the data were presented as mean \pm standard deviation. Statistical comparisons were performed by analysis of variance (ANOVA) for multiple groups, and $p$ value $<0.05$ and $<0.01$ were considered indications of statistical difference and statistically significant difference respectively.

\section{Results and discussions}

\section{Characterization of liposomes}

In order to prove the dual receptor recognizing ability of R8-dGR, three other peptides (R8, R8-RGD and R8-EGR) were utilized herein as controlled peptides. The CPP R8 without a specific binding motif was used as negative control. R8-RGD had an integrin $\mathrm{a}_{\mathrm{v}} \beta_{3}$ binding motif but couldn't recognize NRP-1 receptor without a CendR sequence while R8-EGR was just opposite. The observed molecular weights in the mass spectra of DSPE-PEG $2000-R 8-d G R$, 
DSPE-PEG $2000-R 8-R G D ，$ DSPE-PEG $2000-R 8-E G R$ and DSPE-PEG $2000-R 8$ were 4673, 4631, 4656, and 4308, respectively (See Supplementary Materials Fig. S1-S4) while the corresponding theoretic molecular weights of the four materials were 4640, 4640, 4654, 4312. Liposomes with average sizes between $100 \mathrm{~nm}$ and 120 $\mathrm{nm}$ and polydispersity index (PDI) less than 0.3 were prepared (See Supplementary Materials Table S1). It could be seen that the modification of R8 containing peptide made the liposomes less negative charged due to the electropositivity of polyarginine. PTX could be successfully loaded into the liposomes with entrapment efficiency (EE\%) above 90\%. The size and zeta potential distribution graphs of PTX-R8-dGR-Lip were shown in Fig. 2A and Fig. 2B. No aggregation was observed after $48 \mathrm{~h}$ liposomal incubation with FBS (Fig. 2C), indicating the satisfactory serum stability of different liposomes. The PTX release properties were determined through a dialysis method. The results showed that PTX-loaded liposomes exhibited a sustained drug release behavior over $48 \mathrm{~h}$ while free PTX carried out a rapid release in the media within $8 \mathrm{~h}$ (Fig. 2D). No significant difference was observed among all groups of liposomes.

\section{Surface plasmon resonance (SPR) analysis}

The surface binding of drug delivery systems on cell membranes was considered as the first step of cellular uptake[27]. Thus the evaluation of the interaction efficiency between carriers and proteins on cell membranes was important for nanocarriers, especially for specific ligand modified ones. In this study, we utilized a reversed dGR peptide to create a CendR motif in the tandem peptide. Thus it is necessary to verify whether the sequence reversal would influence
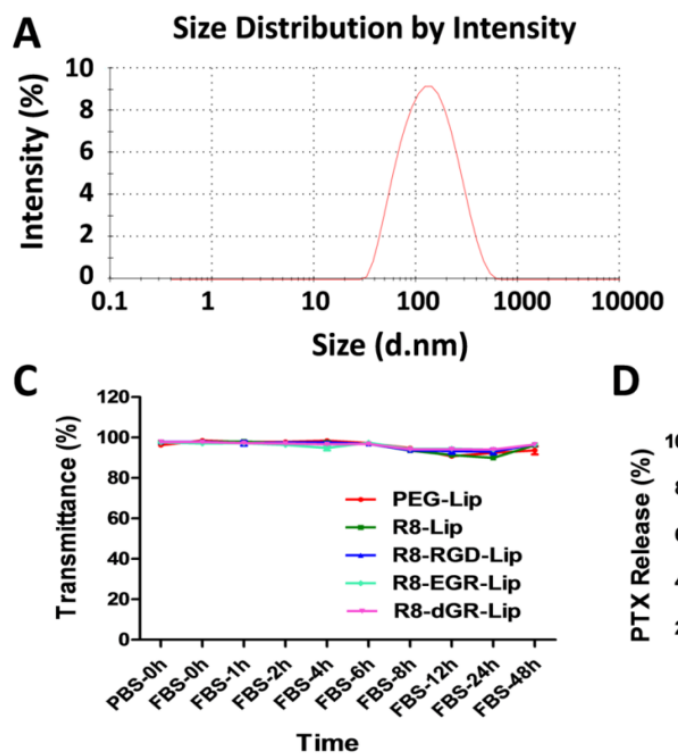

D
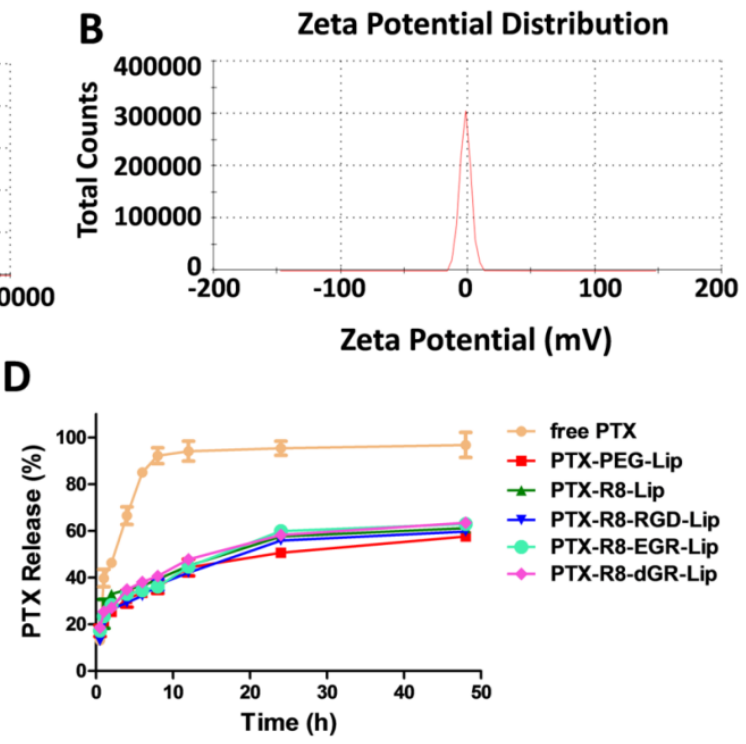

Fig. 2. Characterization of liposomes. Size distribution graph (A) and Zeta potential distribution graph (B) of PTX-R8-dGR-Lip were measured by Malvern Zetasizer Nano ZS90. (C) The variations of transmittance of liposomes in $50 \%$ FBS over $48 \mathrm{~h}(\mathrm{n}=3$, mean \pm SD). (D) PTX release behaviors of PTX-loaded liposomes and free PTX in release media for $48 \mathrm{~h}(\mathrm{n}=3$, mean $\pm S D)$. 


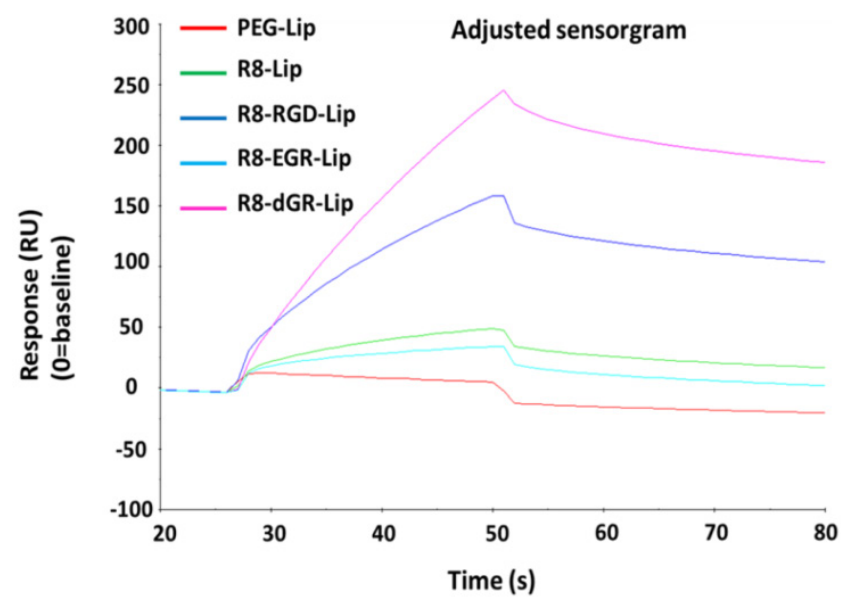

Fig. 3. SPR response curve of different modified liposomes with integrin $\alpha_{v} \beta_{3}$.

\section{Receptor expression level}

The expression level of NRP-1 and integrin $\beta_{3}$ receptors were detected on three cell lines by western blot study (Fig. 4A). As a receptor of vascular endothelial growth factor (VEGF) which regulates the vascular development and tumorigenesis, NRP-1 was usually considered to be overexpressed on both en- dothelial cells and tumor cells[11, 34, 35]. Herein, NRP-1 was found expressed on all the three cell lines. On the other hand, integrin $\beta_{3}$ was found expressed on both C6 cells and bEnd. 3 cells but not on Hela cells as we reported before[18]. The semi-quantitative evaluation of western blot of NRP-1 and integrin $\beta_{3}$ was carried out using ImageJ and the results were shown in Supplementary Materials Fig. S6.

\section{Cellular uptake study}

Receptor-mediated endocytosis is one of the most important mechanisms through which nanoparticulate carriers can overcome the obstacle of BBB and blood brain tumor barrier (BBTB)[36-38]. Thus liposomal uptake was evaluated on these three cell lines as well. Due to the existence of cell penetrating peptide, every R8 containing liposomal group exhibited an enhanced uptake capability compared to the conventional PEG-Lip. On glioma C6 cells and brain endothelial bEnd.3 cells which expressed both neuropilin-1 and integrin $\alpha_{v} \beta_{3}$ receptors, R8-RGD and R8-EGR both significantly increased the cellular uptake of CFPE-labeled liposomes compared to R8-Lip (Fig. 4B).
A

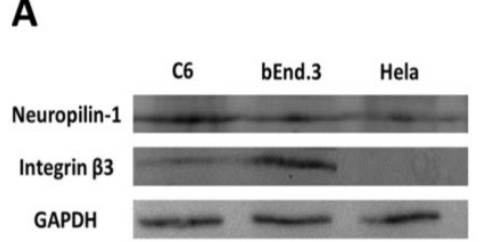

C

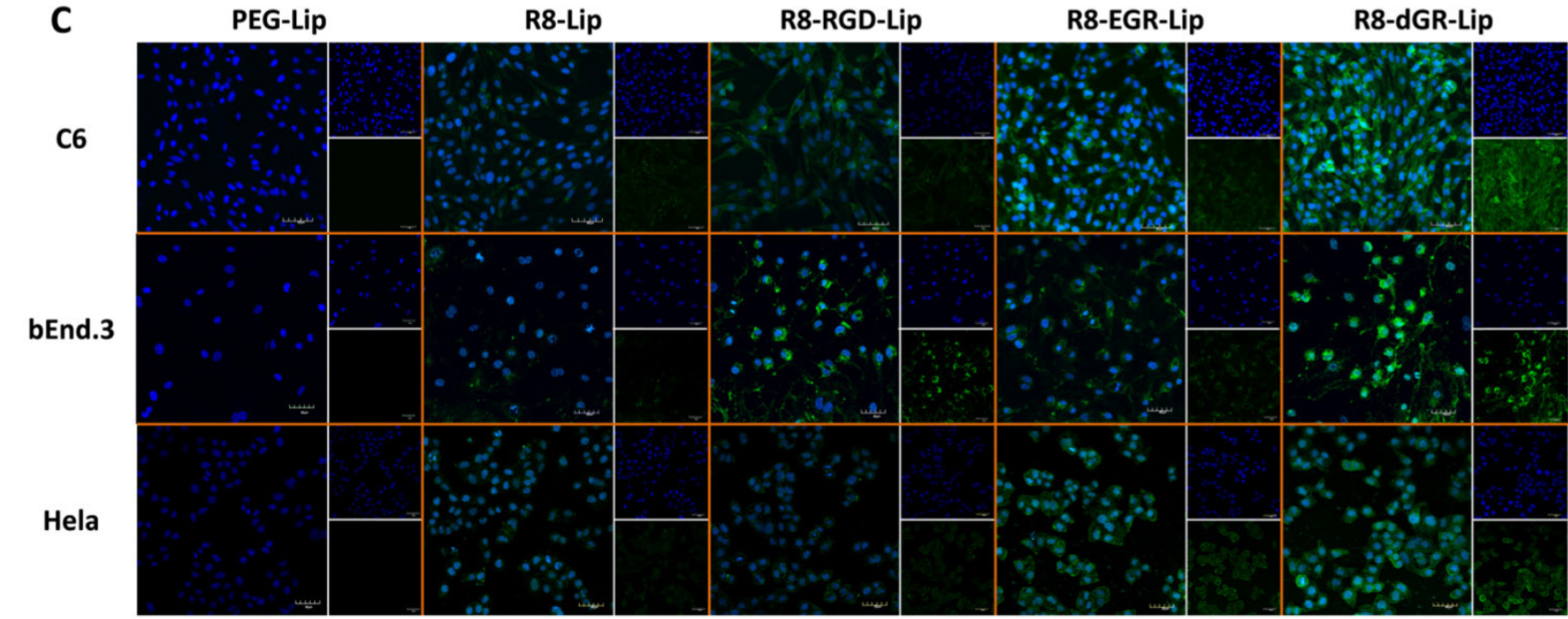

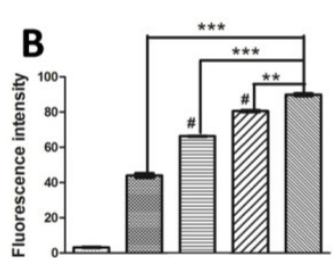

c6

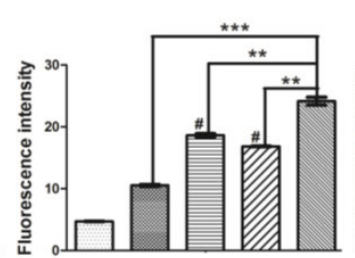

bEnd.3

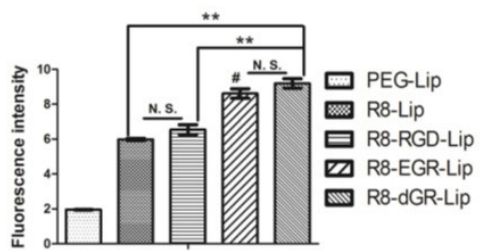

Hela

Fig. 4. (A) Expression level of Neuropilin-1 and integrin $\beta_{3}$ on C6, bEnd.3 and Hela cells. (B) Quantitative 4 h cellular uptake of CFPE-labeled liposomes on C6, bEnd.3 and Hela cells determined by a flow cytometer $(n=3$, mean $\pm S D)$, ** and $* * * *$ indicates $p<0.01$ and $p<0.001$ respectively, \# represents $p<0.05$ versus R8-Lip group. (C) Confocal images of $4 \mathrm{~h}$ cellular uptake of CFPE-labeled liposomes on C6, bEnd. 3 and Hela cells. 
According to the quantitative data, the addition of RGD in the sequence of R8 peptide increased the uptake of R8-Lip by 1.50-fold on C6 cells and 1.77-fold on bEnd.3 cells, while EGR-Lip increased the R8-modified liposomal uptake on C6 cells and bEnd.3 cells by 1.83 -fold and 1.59 -fold respectively. Interestingly, the difference in the uptake enhancement was completely corresponding with the disparity of receptor expression level on different cells. Thus we found that the enhancement of liposomal uptake induced by these tandem peptides was highly dependent on the receptor expression level. Meanwhile, R8-dGR-Lip exhibited the strongest internalization ability among all the liposome groups, indicating the dual receptor recognizing ability of R8-dGR. On the other hand, the cellular uptake on Hela cells between R8-Lip and R8-RGD-Lip didn't show significant difference because of the negative expression of integrin $\alpha_{v} \beta_{3}$. The same phenomenon was found between R8-EGR-Lip and R8-dGR-Lip. However, liposomal uptake was significantly enhanced while the CendR motif was added to the peptide sequence, which further proved the dual receptor dependent endocytosis property of R8-dGR-Lip. Confocal images in Fig. 4C exhibited the same results as described above in which strongest green fluorescence was observed in R8-dGR-Lip group on C6 cells and bEnd.3 cells, indicating R8-dGR as a potential ligand for BBB and glioma targeting.

\section{C6 tumor spheroid uptake}

Three-dimensional tumor spheroids were usually used to mimic a number of native tumor environments including extracellular matrix, tumor macrostructure, and diffusion gradients[39, 40]. Thus tumor spheroid models were established herein to evaluate tumor penetrating ability of liposomes in vitro. C6 spheroids with diameters of 300-400 $\mu \mathrm{m}$ were cultured with CFPE-labeled different modified liposomes for $4 \mathrm{~h}$ and R8-dGR-Lip exhibited the strongest internalization within the spheroids among all the groups (Fig. 5). Green fluorescence signal of R8-dGR-Lip could be observed till $200 \mu \mathrm{m}$ of the tumor spheroids while the penetrating depth of R8-RGD-Lip and R8-EGR-Lip was about $150 \mu \mathrm{m}$ and about $100 \mu \mathrm{m}$ for R8-Lip. Cell penetrating peptides were usually reported to mediate an enhanced intratumoral diffusion process of drug delivery systems [5, 41]. In this study, the penetration and diffusion of liposomes into avascular regions was further elevated when a specific receptor recognizing domain was added to the peptide sequence. For R8-RGD-Lip, the result is similar to our previously published work. The tumor targeting sequence RGD improved the tumor internalization and penetrating ability through the binding to integrin $\alpha_{v} \beta_{3}$. The penetrating of R8-EGR-Lip was even deeper than R8-RGD-Lip as Cend Rule could induce a stronger penetrating behavior than integrin $\alpha_{v} \beta_{3}$. And these results demonstrated the promise of a R8-dGR modification strategy for intratumoral penetration.

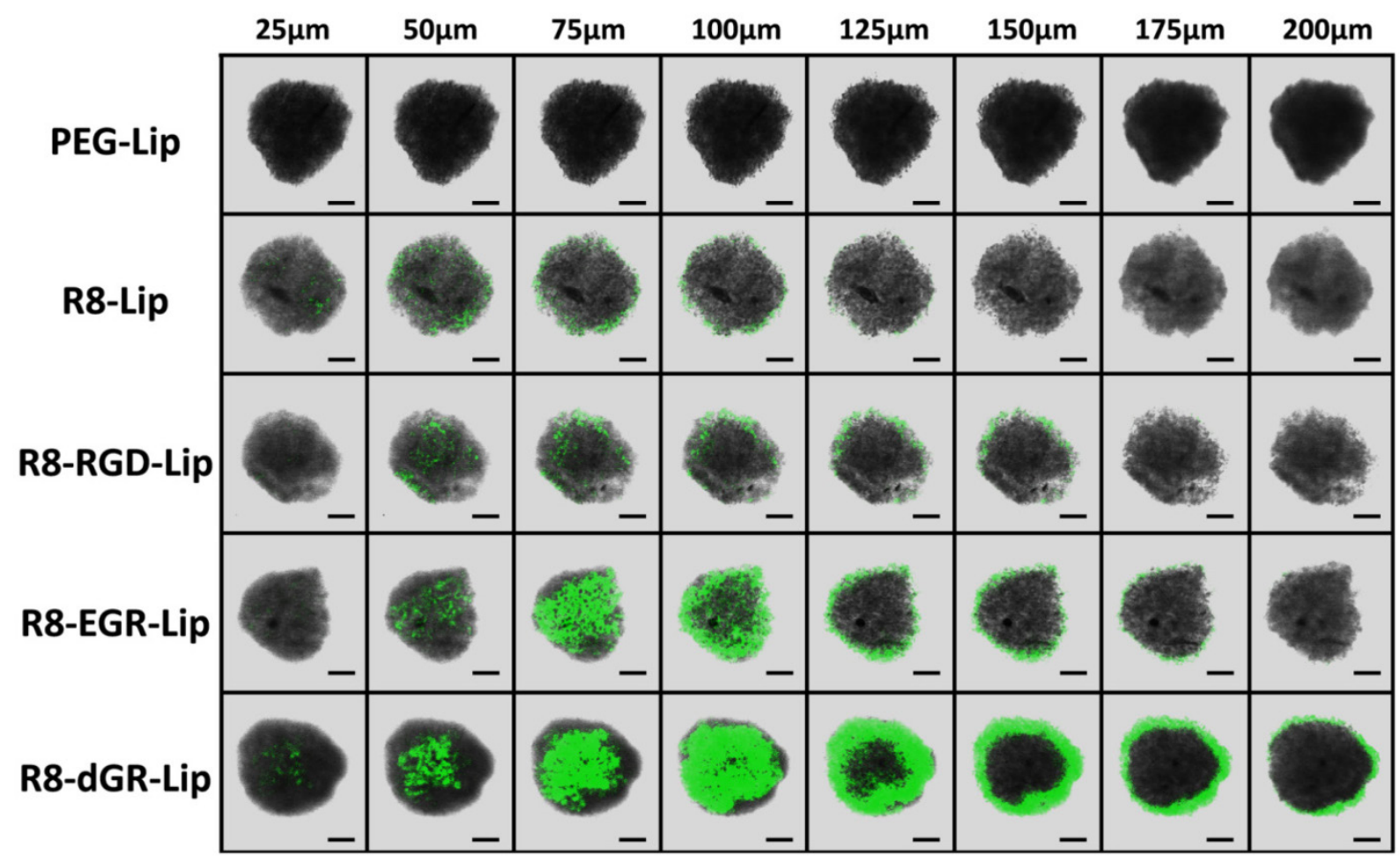

Fig. 5. Confocal images of the uptake of CFPE-labeled liposomes on C6 tumor spheroids with different depth. Scale bars represent $100 \mu \mathrm{m}$. 


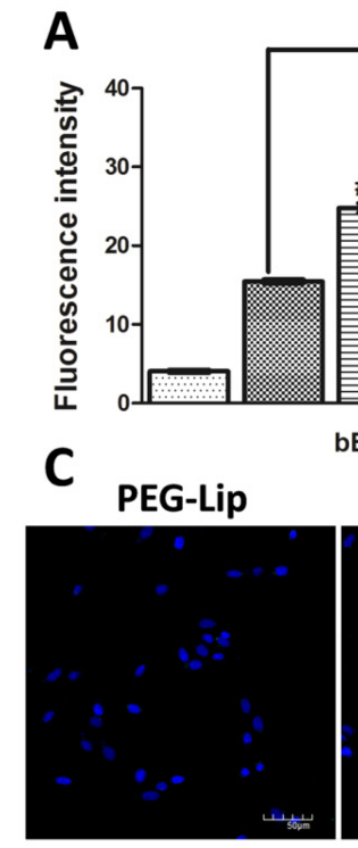

$* * *$

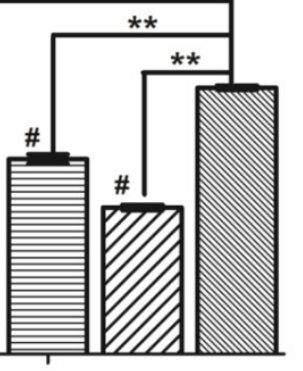

bEnd.3

R8-Lip
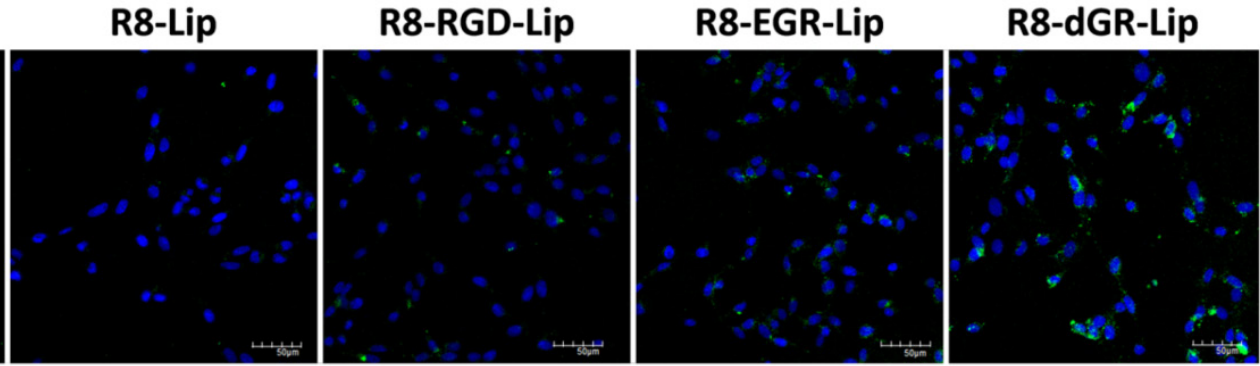

Fig. 6. BBB model study in vitro. Uptake of CFPE-labeled liposomes on bEnd.3 cells on the transwell membrane (A) and on C6 cells in the presence of bEnd.3 monolayers (B) determined by a flow cytometer $(n=3$, mean $\pm S D)$, ** and *** indicates $p<0.01$ and $p<0.001$ respectively, \# represents $p<0.05$ versus $R 8$-Lip group. (C) Confocal images of the liposomal uptake on $\mathrm{C} 6$ cells in the presence of bEnd. 3 monolayers.

\section{BBB model study in vitro}

Transwell models were used to investigate the BBB transporting ability of different modified liposomes in vitro. A bEnd.3 monolayer/C6 co-culture model was utilized here. Effective glioma targeting drug delivery systems were expected to penetrate across the bEnd. 3 monolayer and achieve efficient cellular uptake on C6 cells in the co-culture model. Thus the cellular uptake study on bEnd.3 cells in the donor chamber and on C6 cells in the acceptor chamber were both carried out. As shown in Fig. 6A, the uptake tendency of different liposomes on bEnd.3 monolayer was almost the same as that of the conventional liposomal uptake on bEnd.3 cells in Fig. 4B, indicating a normal internalization process of each group of liposomes on bEnd.3 monolayers from the Transwell membrane. After penetrating across the bEnd.3 monolayer, on the other hand, R8-dGR-Lip exhibited the highest uptake on C6 cells as well (Fig. 6B). Compared to the cellular uptake results on $\mathrm{C} 6$ cells in Fig. 4B, it could be found that the global uptake degree of every group of liposomes was greatly decreased due to the presence of the bEnd.3 monolayer. However, the enhanced percentage of cellular uptake of R8-dGR-Lip compared to R8-RGD-Lip and R8-EGR-Lip was even higher than the conventional liposomal uptake on C6 cells in Fig. 4B. These data confirmed the strongest BBB penetrating capability of R8-dGR compared to the other peptides. Confocal images in Fig. 6C supplied a same result as the quantitative data, in which the strongest uptake on C6 cells of R8-dGR-Lip in the presence of BBB model could be clearly observed.

An immunofluorescence analysis was also carried out to confirm the formation of tight junction on bEnd. 3 monolayer. Zonula occludens protein 1 (ZO-1) is one of the ubiquitous molecular constituents of tight junctions, and it is commonly used for the identification of tight junction on the blood-brain barrier[42, 43]. As shown in Fig. S7, ZO-1 was stained with anti-ZO-1 antibody and was shown in green. The green fluorescence signal between the bEnd.3 cells indicated that tight junction was successfully formed.

\section{Cytotoxicity and apoptosis study in vitro}

MTT study denoted the cytotoxicity of different liposomes on C6 glioma cells. As could be observed in Supplementary Materials Fig. S8, blank liposomal vehicles displayed satisfactory biocompatibility with all the cell viabilities over $85 \%$ after incubation with C6 cells for $24 \mathrm{~h}$ while the solvent of free PTX (ethanol-cremophor ELP 35 mixture, v/v = 1: 1) showed an inhibition as the concentration increased. As for the PTX-loaded liposomes, the MTT assay suggested that the anti-proliferation effect was PTX concentration dependent (Fig. 7A). PTX-loaded R8-RGD-Lip and R8-EGR-Lip displayed increased anti-proliferation effect compared to R8-Lip and conventional PEG-Lip, and PTX-R8-dGR-Lip exhibited the strongest inhibition effect among all the PTX formulations, even stronger than free PTX. Free drugs were usually used as positive controlled group in cytotoxicity study because they could be delivered into cells directly by 
passive diffusion[44, 45], while drug carriers would inevitably undergo a sustained drug release process (Fig. 2D). Thus the MTT study confirmed that R8-dGR could most notably promote the cellular endocytosis of PTX-loaded liposomes. The $\mathrm{IC}_{50}$ values of different PTX formulations were listed in Supplementary Materials Table S2. On the other hand, Annexin V/PI dual staining was utilized to carry out the apoptosis study. The cellular apoptosis dot diagrams of C6 cells after incubation with or without different PTX formulations were shown in Supplementary Materials Fig. S9. The apoptosis and necrosis rates of C6 cells after treated with free PTX, PTX-PEG-Lip, PTX-R8-Lip, PTX-R8-RGD-Lip, PTX-R8-EGR-Lip and PTX-R8-dGR-Lip for $24 \mathrm{~h}$ were $75.65 \pm 1.77 \%, 62.25 \pm$ $1.48 \%, 72.05 \pm 1.49 \%, 76.50 \pm 3.25 \%, 76.65 \pm 1.57 \%$ and $91.05 \pm 0.35 \%$, respectively (Fig. 7B). Therefore, based on all the cytotoxicity and apoptosis study, R8-dGR had proved the capability to induce a significant enhanced inhibition of glioma cellular growth.

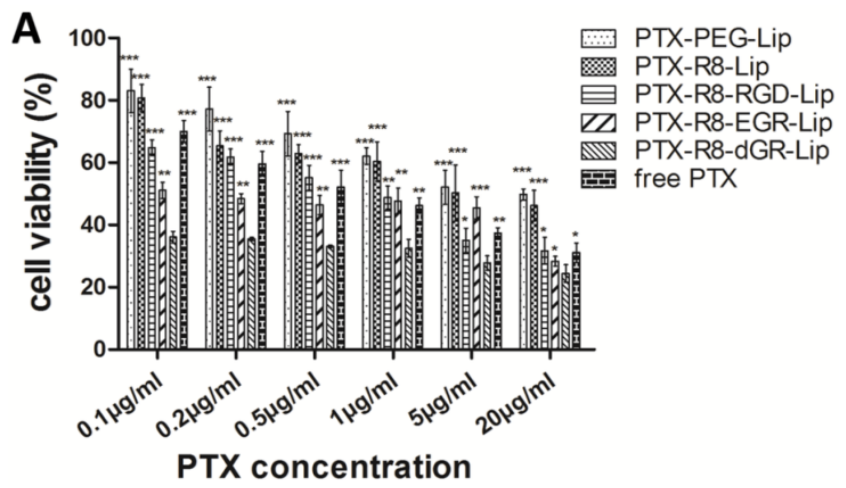

B

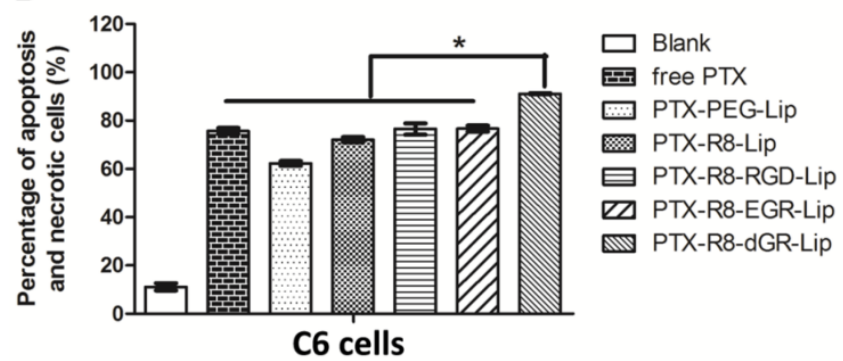

Fig. 7. (A) The cytotoxicity study of different PTX formulations on C6 cells $(n=3$, mean $\pm \mathrm{SD}$ ). ${ }^{*}, * *$ and $* * *$ represent $p<0.05, p<0.01$ and $p<0.001$ versus PTX-R8-dGR-Lip group, respectively. (B) The percentage of apoptosis and necrotic cells after different PTX formulations treatment $(n=3$, mean \pm SD), * represents $p<$ 0.05 versus other groups.

\section{Destruction of VM channels}

Matrigel based tube formation model was used to investigate the formation of vasculogenic mimicry channels in vitro as reported[24, 46]. VM describe a mechanism by which tumor cells, especially highly aggressive malignant tumor cells, can form vessel-like structures themselves and function as an alternative blood and nutrients transporting pathway[20, 46, 47].
Thus the evaluation of VM channels destruction in vitro with the treatment of different PTX formulations was necessary. Glioma cells were reported to display a high degree of plasticity, which made them capable to differentiate and form tube-like structures[46, 48, 49]. As shown in Fig. 8A, in control group without PTX treatment, C6 cells would start to aggregate and turn fascicular $6 \mathrm{~h}$ after plated onto the surface of Matrigel, and further form long and apparent tubular structures after $24 \mathrm{~h}$ incubation. When different PTX formulations were added to the culture medium, the formation of VM channels was obviously inhibited. Glioma cells could only exhibit the tendency to adjoin each other within $6 \mathrm{~h}$ and finally form disconnected tube analogues 24 hours later in the PTX-treated groups. However, in the PTX-R8-dGR-Lip group, the cells always displayed scattered distribution instead of aggregation, and the formation of VM channels was interrupted. This destructive effect might be resulting from the cytotoxicity of PTX-loaded R8-dGR-Lip against C6 glioma cells, and the inhibition effect of VM formation in vivo was further addressed in the following pharmacodynamics study.

\section{Characterization and Cytotoxicity study of brain cancer stem cells}

Cancer stem cells were usually correlated with drug resistance and relapse of malignant tumors[26]. Thus brain cancer stem cells were cultured and the cytotoxicity of liposomes on them was evaluated here. BCSCs were cultured and identified through both morphological observation and phenotypical detecting as reported[25]. After continuous culture in serum free culture medium for 3 weeks, BCSCs would present as suspended mammospheres under a microscope[22, 25]. As shown in Fig. 8B, the tumor spheres of C6 stem cells exhibited uniformly at diameters of about 50-100 $\mu \mathrm{m}$. Meanwhile, the inherent nature of cancer stem cells was the positive expression of Prominin-1 (CD133) which was related to the tumorigenic potential of CSCs[19, 25]. Thus the expression level of CD133 on C6 glioma cells and the cultured C6 stem cells was detected here using western blot study. The CD133 expressed on C6 stem cells was obviously increased compared to normal C6 glioma cells (Fig. 8C), indicating that BCSCs were successfully formed in serum free culture medium. The semi-quantitative evaluation of western blot of CD133 was carried out using Image and the result was shown in Supplementary Materials Fig. S10. Finally, the C6 stem cells were utilized to evaluate the cytotoxicity of PTX formulations on BCSCs in vitro. The results of MTT assay was shown in Fig. 8D. Compared to the cellular cytotoxicity on C6 glioma cells (Fig. 7A), it could be observed that the tolerance of the tumor stem cells to 
chemotherapeutics was significantly enhanced $\left(\mathrm{IC}_{50}\right.$ values were listed in Supplementary Materials Table S2). All the C6 stem cells treated with PTX formulations with a concentration below $0.5 \mu \mathrm{g} / \mathrm{mL}$ exhibited cell viabilities over $70 \%$, which was due to the fact that cancer stem cells contribute to chemotherapy resistance[50, 51]. As the PTX concentration increased, the disparity between different modified liposomes became more significant. PTX-R8-dGR-Lip displayed a remarkable enhanced cytotoxicity to C6 stem cells compared to the other groups, which might be due to the improved internalization ability. All the in vitro experiments suggested the potential of R8-dGR modified liposomes as a drug delivery system for synthesized anti-glioma therapy.

\section{In vivo imaging and glioma distribution}

Fig. 9A and Fig. 9B displayed the in vivo images and $e x$ vivo brains of $\mathrm{C} 6$ glioma bearing mice after systemic administration of different DiR-loaded liposomes. CPPs and specific ligands had both proved their advantages for BBB penetrating in many researches[52-55]. In this study, the tandem peptides (R8-RGD, R8-EGR and R8-dGR) could undergo both receptor-dependent and adsorptive-mediated $\mathrm{BBB}$ transporting process thus they exhibited increased brain delivery capabilities compared to R8 (Fig. 9A). And it could be observed that the fluorescence signal of R8-dGR-Lip in the brain was the strongest among all the groups. Furthermore, as integrin $\alpha_{v} \beta_{3}$ and NRP-1 receptors are overexpressed on both angiogenic tumor vessels and tumor cells[11, 56, 57], we suggested the dual recognizing tandem peptide R8-dGR could promote an active glioma targeting process and the results proved this hypothesis. The ex vivo brain images in Fig. 9B demonstrated that R8-dGR modified liposomes not only showed the strongest brain delivery, but also accumulated at the glioma foci most efficiently. Images of other organs were shown in Supplementary Materials Fig. S11.

Drugs must cross the vascular barrier and penetrate into the extravascular stroma to reach the inner tumor cells and tumor-associated parenchymal cells[58]. Therefore we then investigated the glioma distribution of the modified liposomes. According to the in vivo images, DiR-loaded liposomes achieved the highest accumulation at the glioma foci $24 \mathrm{~h}$ after systemic administration. Thus the brains of $24 \mathrm{~h}$ post-injection mice were sectioned and the inner glioma sites were imaged using a confocal microscope. Obvious red fluorescence signal was detected in the R8-dGR-Lip group (Fig. 9C), indicating an elevated accumulation and wide distribution of R8-dGR modified liposomes in the glioma tissue. The semi-quantitative results of the confocal images of glioma sections were analyzed using ImageJ and were shown in Supplementary Materials Fig. S12.

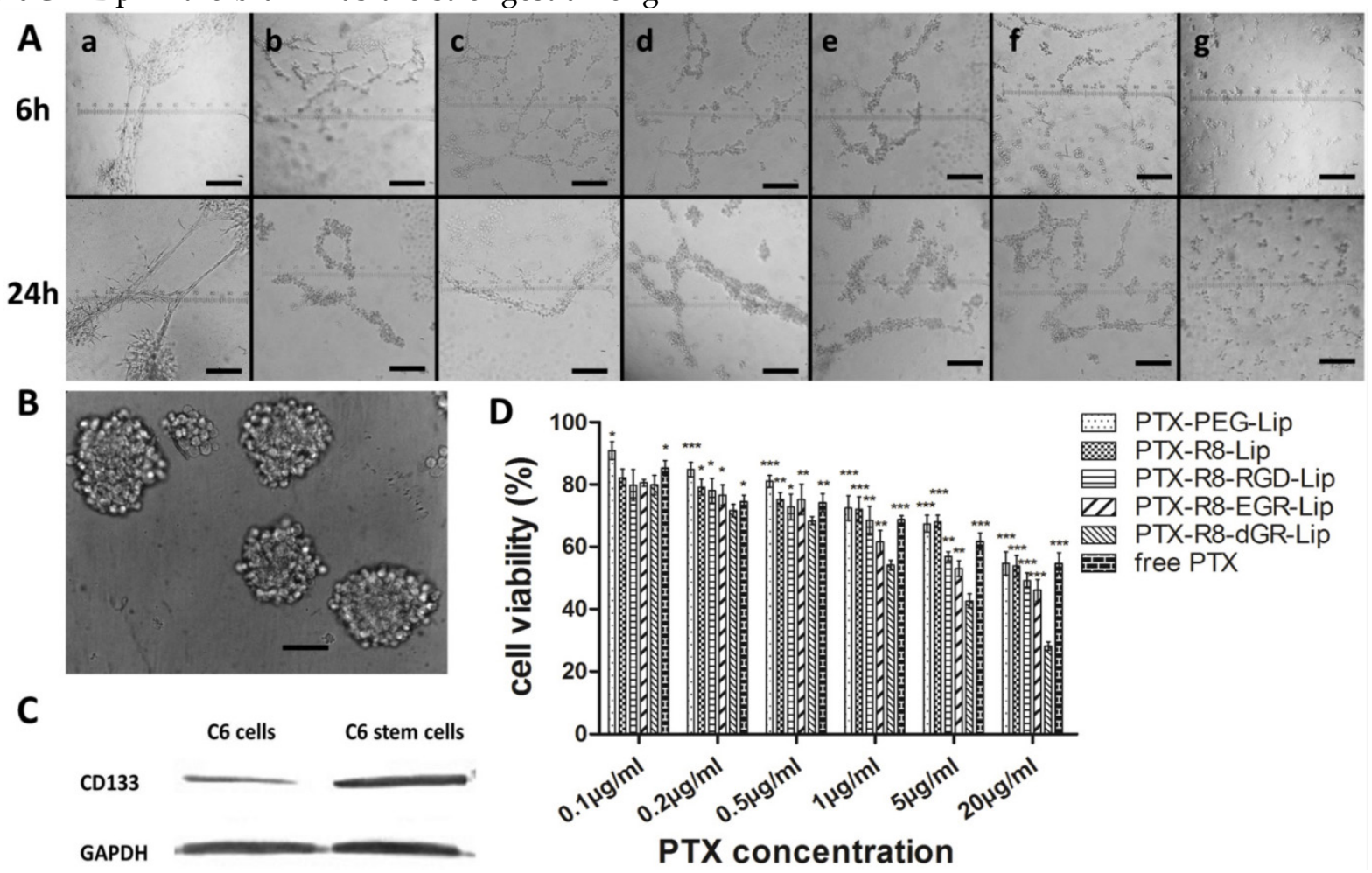

Fig.8. (A) Destruction of C6 VM channels in vitro after $6 \mathrm{~h}$ and $24 \mathrm{~h}$ treatment of free PTX and PTX-loaded liposomes, untreated group was used as negative control. a $=$ Saline, $b=$ free PTX, c = PTX-PEG-Lip, $d=$ R8-Lip, e = PTX-R8-RGD-Lip, $f=$ PTX-R8-EGR-Lip, $g$ = PTX-R8-dGR-Lip. Scale bars represent 200 $\mu m$. (B) Morphological identification of C6 stem cell tumor spheres. Scale bar represents $50 \mu \mathrm{m}$. (C) CDI33 expression level on C6 cells and C6 stem cells. (D) The cytotoxicity study of different PTX formulations on C6 stem cells $(n=3$, mean \pm SD). *, ** and $* * *$ represent $p<0.05, p<0.01$ and $p<0.001$ versus PTX-R8-dGR-Lip group, respectively. 


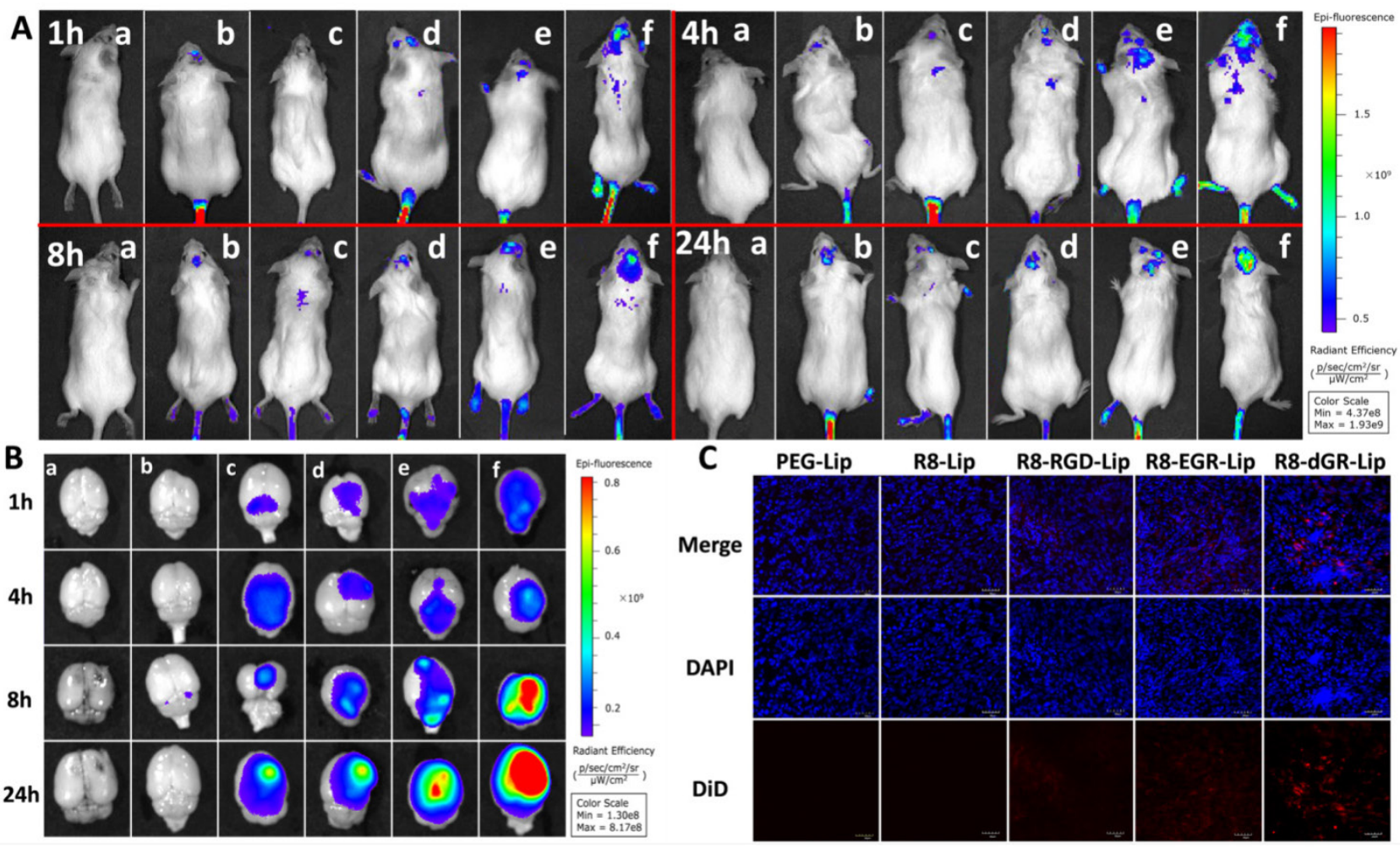

Fig. 9. (A) In vivo images of intracranial $\mathrm{C} 6$ glioma bearing mice at $1 \mathrm{~h}, 4 \mathrm{~h}, 8 \mathrm{~h}$ and $24 \mathrm{~h}$ post-injection of DiD-loaded liposomes. (B) Ex vivo images of the glioma bearing brains. In (A) and (B), a = blank, b = PEG-Lip, c = R8-Lip, d = R8-RGD-Lip, e = R8-EGR-Lip, f = R8-dGR-Lip. (C) Confocal images of glioma sections of C6 bearing mice 24 h after systemic administration of DiD-loaded liposomes.

Researchers suggested that CendR peptides would contribute to extravasation of the payload and penetration into tumor tissue through an NRP-1-binding pathway[58], and in this study it was proved that dual receptor recognizing ability would further enhance the progressive penetration. These in vivo results demonstrated that the dual receptor recognizing cell penetrating peptide R8-dGR possessed superior BBB transporting, glioma targeting and efficient tumor penetrating capabilities, and these properties would benefit the anti-glioma therapy effect of drug loaded liposomes.

\section{Anti-glioma efficacy}

Kaplan-Meier survival curves (Fig. 10A) demonstrated a prolonged survival time of modified liposomes. The medium survival time glioma bearing mice treated with PTX-R8-dGR-Lip group (40 days) was significant longer than that of saline (19 days), free PTX (29 days), PTX-PEG-Lip (27 days), PTX-R8-Lip (29 days), PTX-R8-RGD-Lip (35 days) and PTX-R8-EGR-Lip (30 days) (Table 1). Then the synthesized anti-glioma therapeutic efficacy was evaluated through several staining of different glioma sections. Hematoxylin-eosin staining (HE staining) in Fig.10B exhibited large tracts of tumor tissue in the saline-treated group, while the color in PTX formulation treated groups was shallower. The most signifi- cant reduction of glioma area was observed in the PTX-R8-dGR-Lip group, indicating an increased anti-proliferation effect of tumor cells induced by R8-dGR in vivo. On the other hand, CD34-PAS dual staining was used for detecting VM channels in vivo. CD34 was used to mark endothelial and endothelial progenitor cells while PAS could stain vascular basement membranes[21, 46]. Therefore, the non-endothelial tumor cell-lined VM microvascular channels would be PAS-positive and CD34-negative and reflect as pink tubes. Fig. 10C demonstrated obvious decrease of VM channels in the PTX-R8-dGR-Lip group while long and clear tubular structures were observed in other groups. As VM channels functioned as an alternative blood supply network, the destruction of VM could cut off the nutrients transporting and contribute to an enhanced anti-tumor effect, especially to the aggressive malignant tumors[59, 60]. Finally, CD133 immuno histochemical staining was carried out to identify BCSCs. As shown in Fig. 10D, a crowd of CD133 positive cancer stem cells stained in brown was observed in saline group. After treatment of PTX formulations, stem cells were decreased in different degrees. However, CD133 negative cells shown in blue were observed instead in the R8-dGR modified liposome group, indicating the most efficient anti-cancer stem cells effect of PTX-R8-dGR-Lip. Meanwhile, we had 
detected the expression level of integrin $\alpha_{v} \beta_{3}$ and neuropilin-1 on C6 stem cells as well, and no significant difference was found between C6 cells and C6 stem cells (Data not shown). The only difference between C6 cells and BCSCs was the increase expression of CD133. Therefore, R8-RGD-Lip and R8-EGR-Lip could also achieve enhanced toxicity to BCSCs through integrin and NRP-1 mediated cellular internalization respectively. In conclusion, PTX-loaded liposomes decorated with the dual receptor recognizing peptide R8-dGR displayed an efficient synthesized anti-glioma effect including anti-tumor cells, anti-VM and anti-BCSCs, which would probably lead to an exhaustive therapeutic efficacy and prevention of glioma relapse.

\section{Conclusion}

In this study, we have designed a PTX-loaded liposomal drug delivery system modified with a tandem peptide R8-dGR. As a dual receptor recognizing cell penetrating peptide, R8-dGR displayed strong $\mathrm{BBB}$ transporting, glioma targeting and penetrating capabilities. Based on these properties, PTX-R8-dGR-Lip exhibited synthesized anti-glioma therapeutic effects including anti-tumor cells, anti-VM and anti-BCSCs. Therefore, we suggested the R8-dGR modified liposomes as a potential drug delivery system for anti-tumor therapy.

Table 1. The median survival time of the glioma bearing mice treated with different PTX formulations ( ${ }^{a} p<0.05$ versus Saline, $b p$ $<0.05$ versus free PTX, $q<0.05$ versus PTX-PEG-Lip, ${ }^{d} p<0.05$ versus PTX-R8-Lip, ep $<0.05$ versus PTX-R8-RGD-Lip, $f p<0.05$ versus PTX-R8-dGR-Lip).

\begin{tabular}{llllll}
\hline Group & $\begin{array}{l}\text { Median } \\
\text { (day) }\end{array}$ & $\begin{array}{l}\text { Standard } \\
\text { error }\end{array}$ & $\begin{array}{l}\text { 95\% confi- } \\
\text { dence } \\
\text { interval }\end{array}$ & Significant & $\begin{array}{l}\text { Increased } \\
\text { survival } \\
\text { time }\end{array}$ \\
\hline Saline & 19 & 2.2 & $16.3-24.9$ & -- & -- \\
free PTX & 29 & 2.3 & $22.2-31.1$ & a & $53 \%$ \\
PTX-PEG-Lip & 27 & 2.3 & $20.5-29.5$ & a & $42 \%$ \\
PTX-R8-Lip & 29 & 2.7 & $23.8-34.4$ & a & $53 \%$ \\
PTX-R8-RGD-Lip & 35 & 3.0 & $28.2-39.8$ & a,b,c,d & $84 \%$ \\
PTX-R8-EGR-Lip & 30 & 3.0 & $23.6-35.5$ & a & $58 \%$ \\
PTX-R8-dGR-Lip & 40 & 3.1 & $33.2-45.5$ & a,b,c,d,e,f & $110 \%$ \\
\hline
\end{tabular}

A
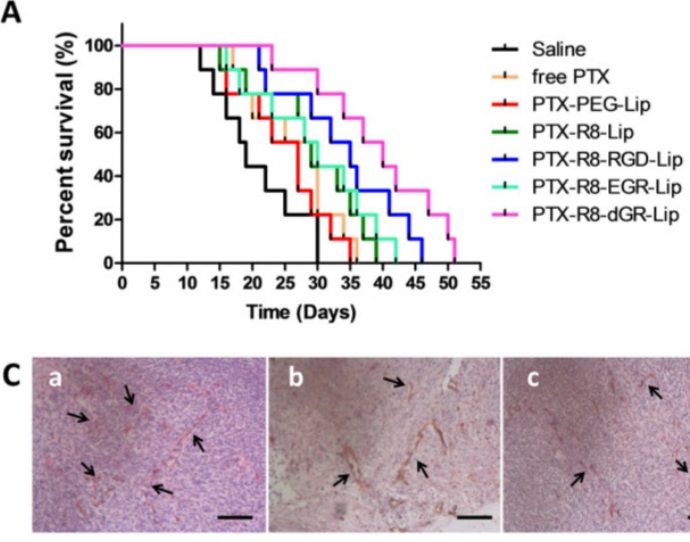

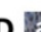

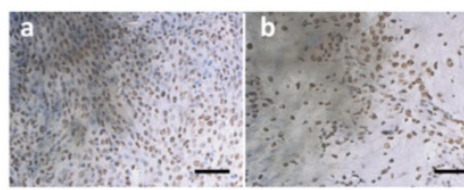

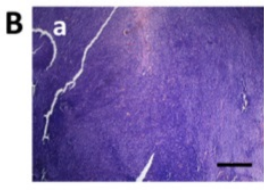
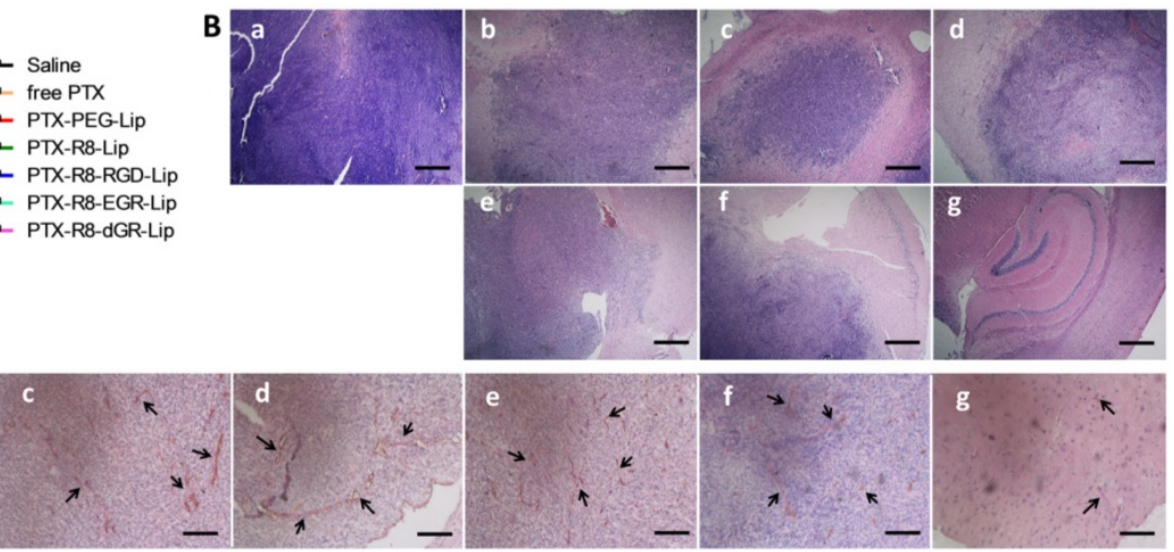

g
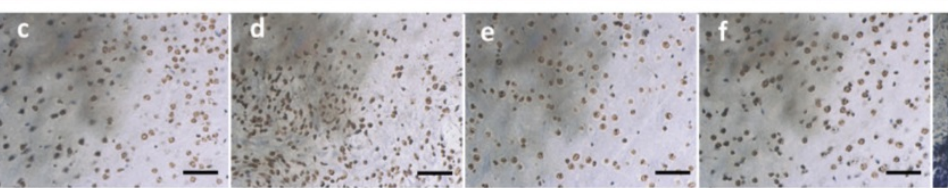

Fig. 10. The anti-glioma assay of PTX-loaded liposomes on intracranial C6 bearing mice. (A) Kaplan-Meier survival curve of intracranial C6 glioma bearing mice treated with different PTX formulations ( $n=9$ ). Saline group was used as negative control. Red arrows indicate times of treatment. (B) HE staining of brain glioma tissues. Scale bars represent $400 \mu \mathrm{m}$. (C) CD34-PAS dual staining of brain glioma tissues. Scale bars represent $200 \mu \mathrm{m}$. Black arrows indicate pink vasculogenic mimicry in vivo. (D) CD133 staining of brain glioma tissues. Scale bars represent $50 \mu \mathrm{m}$. Brain cancer stem cells with CD133 positive expression were shown in brown. In $(B)-(D), a=S a l i n e, b=$ free PTX, $c=$ PTX-PEG-Lip, $\mathrm{d}$ = R8-Lip, e = PTX-R8-RGD-Lip, $\mathrm{f}=$ PTX-R8-EGR-Lip, $\mathrm{g}$ = PTX-R8-dGR-Lip.

\section{Supplementary Material}

Figures S1- S12, Tables S1-S2.

http://www.thno.org/v06p0177s1.pdf

\section{Acknowledgements}

The work was funded by the National Basic Research Program of China (973 Program, 2013CB932504), the National Natural Science Foun- dation of China (81373337), and the Sichuan Province Infrastructure Platform of Science and Technology (15010116).

\section{Abbreviations}

CPP: cell penetrating peptide; BBB: blood-brain barrier; IFP: interstitial fluid pressure; NRP-1: neuropilin-1; VM: vasculogenic mimicry; BCSCs: brain cancer stem cells; PTX: paclitaxel; SPC: Soybean 
phospholipids; CFPE: 1,2-dioleoyl-sn-glycero-3phosphoethanolamine-N-(carboxyfluorescein); HRP: horseradish peroxidase; DiD: 1, 10-dioctadecyl- 3, 3, 30, 30-tetramethylindodicarbocyanine, 4-chlorobenzenesulfonate salt; SPR: surface plasmon resonance; FBS: fetal bovine serum; TEER: transendothelial electric resistance; MTT: 3-(4,5-dimethylthiazol-2-yl)2,5-diphenyltetrazolium bromide; PAS: periodic acid-Schiff; PDI: polydispersity index; EE: entrapment efficiency; VEGF: vascular endothelial growth factor; BBTB: blood brain tumor barrier; ZO-1: zonula occludens protein 1; CD133: prominin-1.

\section{Competing Interests}

The authors have declared that no competing interest exists.

\section{References}

1. Milletti F. Cell-penetrating peptides: classes, origin, and current landscape. Drug discovery today. 2012; 17: 850-60.

2. Huang $Y$, Jiang $Y$, Wang $H$, Wang J, Shin MC, Byun $Y$, et al Curb challenges of the "Trojan Horse" approach: Smart strategies in achieving effective yet safe cell-penetrating peptide-based drug delivery. Advanced drug delivery reviews. 2013; 65: 1299-315.

3. Kuai R, Yuan W, Li W, Qin Y, Tang J, Yuan M, et al. Targeted delivery of cargoes into a murine solid tumor by a cell-penetrating peptide and cleavable poly (ethylene glycol) comodified liposomal delivery system via systemic administration. Molecular pharmaceutics. 2011; 8: 2151-61.

4. Biswas S, Deshpande PP, Perche F, Dodwadkar NS, Sane SD, Torchilin VP. Octa-arginine-modified pegylated liposomal doxorubicin: an effective treatment strategy for non-small cell lung cancer. Cancer letters. 2013; 335: 191-200.

5. Wang H, Zhao $\mathrm{Y}$, Wang $\mathrm{H}$, Gong J, He H, Shin $\mathrm{MC}$, et al. Low-molecular-weight protamine-modified PLGA nanoparticles for overcoming drug-resistant breast cancer. Journal of Controlled Release. 2014; 192: 47-56.

6. Jiang X, Xin $\mathrm{H}, \mathrm{Gu} \mathrm{J}, \mathrm{Xu} X, \mathrm{Xia} W$, Chen $\mathrm{S}$, et al. Solid tumor penetration by integrin-mediated pegylated poly (trimethylene carbonate) nanoparticles loaded with paclitaxel. Biomaterials. 2013; 34: 1739-46.

7. Wu W, Driessen W, Jiang X. Oligo (ethylene glycol)-Based Thermosensitive Dendrimers and Their Tumor Accumulation and Penetration. Journal of the American Chemical Society. 2014; 136: 3145-55.

8. Wen Y, Meng WS. Recent In Vivo Evidences of Particle-Based Delivery of Small-Interfering RNA (siRNA) into Solid Tumors. Journal of pharmaceutical innovation. 2014; 9: 158-73.

9. Wen Y, Roudebush SL, Buckholtz GA, Goehring TR, Giannoukakis N, Gawalt ES, et al. Coassembly of amphiphilic peptide EAK16-II with histidinylated analogues and implications for functionalization of $\beta$-sheet fibrils in vivo. Biomaterials. 2014; 35: 5196-205.

10. Ju C, Mo R, Xue J, Zhang L, Zhao Z, Xue L, et al. Sequential Intra-Intercellular Nanoparticle Delivery System for Deep Tumor Penetration. Angewandte Chemie International Edition. 2014; 53: 6253-8.

11. Teesalu T, Sugahara KN, Kotamraju VR, Ruoslahti E. C-end rule peptides mediate neuropilin-1-dependent cell, vascular, and tissue penetration. Proceedings of the National Academy of Sciences. 2009; 106: 16157-62.

12. Nasarre C, Roth M, Jacob L, Roth L, Koncina E, Thien A, et al. Peptide-based interference of the transmembrane domain of neuropilin- 1 inhibits glioma growth in vivo. Oncogene. 2010; 29: 2381-92

13. OSADA H, TOKUNAGA T, NISHI M, HATANAKA H, ABE Y, TSUGU A, et al. Overexpression of the neuropilin 1 (NRP1) gene correlated with poor prognosis in human glioma. Anticancer research. 2004; 24: 547-52.

14. Alberici L, Roth L, Sugahara KN, Agemy L, Kotamraju VR, Teesalu T, et al. De novo design of a tumor-penetrating peptide. Cancer research. 2013; 73: 804-12.

15. Sugahara KN, Teesalu T, Karmali PP, Kotamraju VR, Agemy L, Girard OM, et al. Tissue-penetrating delivery of compounds and nanoparticles into tumors. Cancer cell. 2009; 16: 510-20.

16. Wang J, Lei Y, Xie C, Lu W, Wagner E, Xie Z, et al. Retro-Inverso CendR Peptide-Mediated Polyethyleneimine for Intracranial Glioblastoma-Targeting Gene Therapy. Bioconjugate chemistry. 2014; 25: 414-23.

17. Yang Z-Z, Li J-Q, Wang Z-Z, Dong D-W, Qi X-R. Tumor-targeting dual peptides-modified cationic liposomes for delivery of siRNA and docetaxel to gliomas. Biomaterials. 2014; 35: 5226-39.

18. Liu Y, Ran R, Chen J, Kuang Q, Tang J, Mei L, et al. Paclitaxel loaded liposomes decorated with a multifunctional tandem peptide for glioma targeting. Biomaterials. 2014; 35: 4835-47.
19. de Mendoza FH, Rodriguez EA. Cancer Stem Cells in Brain Tumors. Stem Cells in Cancer: Should We Believe or Not? Springer; 2014: 229-43.

20. El Hallani S, Boisselier B, Peglion F, Rousseau A, Colin C, Idbaih A, et al. A new alternative mechanism in glioblastoma vascularization: tubular vasculogenic mimicry. Brain. 2010; 133: 973-82.

21. Liu X-m, Zhang Q-p, Mu Y-g, Zhang X-h, Sai K, Pang JC-S, et al. Clinical significance of vasculogenic mimicry in human gliomas. Journal of neuro-oncology. 2011; 105: 173-9.

22. Yan $\mathrm{K}, \mathrm{Wu} \mathrm{Q}, \mathrm{Yan} \mathrm{DH}$, Lee $\mathrm{CH}$, Rahim N, Tritschler I, et al. Glioma cancer stem cells secrete Gremlin1 to promote their maintenance within the tumor hierarchy. Genes \& development. 2014; 28: 1085-100.

23. Paulis YW, Soetekouw PM, Verheul HM, Tjan-Heijnen VC, Griffioen AW. Signalling pathways in vasculogenic mimicry. Biochimica et Biophysica Acta (BBA)-Reviews on Cancer. 2010; 1806: 18-28.

24. Ling G, Wang S, Song Z, Sun X, Liu Y, Jiang X, et al. Transforming growth factor-b is required for vasculogenic mimicry formation in glioma cell line U251MG. Cancer biology \& therapy. 2011; 12: 978-88.

25. Bao S, Wu Q, McLendon RE, Hao Y, Shi $\mathrm{Q}$, Hjelmeland AB, et al. Glioma stem cells promote radioresistance by preferential activation of the DNA damage response. Nature. 2006; 444: 756-60

26. Mann A, van Ommeren R, Manoranjan B, McFarlane N, Vora P, Venugopal C, et al. Glioblastoma Stem Cells Drive Tumor Recurrence and Patient Relapse: What's the Evidence? Cancer Stem Cells. 2014: 193-208.

27. Guo Z, He B, Jin H, Zhang H, Dai W, Zhang L, et al. Targeting efficiency of RGD-modified nanocarriers with different ligand intervals in response to integrin av 33 clustering. Biomaterials. 2014; 35: 6106-17.

28. Cai D, Gao W, He B, Dai W, Zhang H, Wang X, et al. Hydrophobic penetrating peptide PFVYLI-modified stealth liposomes for doxorubicin delivery in breast cancer therapy. Biomaterials. 2014; 35: 2283-94.

29. Li M-H, Choi SK, Leroueil P, Baker JR. Evaluating Binding Avidities of Populations of Heterogeneous Multivalent Ligand-Functionalized Nanoparticles. ACS nano. 2014; 8: 5600-9.

30. Pattnaik P. Surface plasmon resonance. Applied biochemistry and biotechnology. 2005; 126: 79-92.

31. Wermuth J, Goodman S, Jonczyk A, Kessler H. Stereoisomerism and biological activity of the selective and superactive av $\beta 3$ integrin inhibitor cyclo (-RGDfV-) and its retro-inverso peptide. Journal of the American Chemical Society. 1997; 119: 1328-35.

32. Goodman M, Chorev M. On the concept of linear modified retro-peptide structures. Accounts of Chemical Research. 1979; 12: 1-7.

33. Li Y, Lei Y, Wagner E, Xie C, Lu W, Zhu J, et al. Potent retro-inverso D-peptide for simultaneous targeting of angiogenic blood vasculature and tumor cells. Bioconjugate chemistry. 2013; 24: 133-43.

34. Esquibies AE, Karihaloo A, Quaggin SE, Bazzy-Asaad A, Cantley LG. Heparin binding VEGF isoforms attenuate hyperoxic embryonic lung growth retardation via a FLK1-neuropilin-1-PKC dependent pathway. Respiratory research. 2014; $15: 32$.

35. Soker S, Takashima S, Miao HQ, Neufeld G, Klagsbrun M. Neuropilin-1 is expressed by endothelial and tumor cells as an isoform-specific receptor for vascular endothelial growth factor. Cell. 1998; 92: 735-45.

36. Chen Y, Liu L. Modern methods for delivery of drugs across the blood-brain barrier. Advanced drug delivery reviews. 2012; 64: 640-65.

37. Wang B, Lv L, Wang Z, Zhao Y, Wu L, Fang X, et al. Nanoparticles functionalized with Pep-1 as potential glioma targeting delivery system via interleukin 13 receptor a2-mediated endocytosis. Biomaterials. 2014; 35: 5897-907.

38. $\mathrm{Xu} \mathrm{S}$, Olenyuk BZ, Okamoto CT, Hamm-Alvarez SF. Targeting receptor-mediated endocytotic pathways with nanoparticles: rationale and advances. Advanced drug delivery reviews. 2013; 65: 121-38.

39. Charoen KM, Fallica B, Colson YL, Zaman MH, Grinstaff MW. Embedded multicellular spheroids as a biomimetic 3D cancer model for evaluating drug and drug-device combinations. Biomaterials. 2014; 35: 2264-71.

40. Gibot L, Wasungu L, Teissié J, Rols M-P. Antitumor drug delivery in multicellular spheroids by electropermeabilization. Journal of Controlled Release. 2013; 167: 138-47.

41. Zhang Q, Tang J, Fu L, Ran R, Liu Y, Yuan M, et al. A pH-responsive a-helical cell penetrating peptide-mediated liposomal delivery system. Biomaterials. 2013; 34: 7980-93.

42. Abbott NJ, Rönnbäck L, Hansson E. Astrocyte-endothelial interactions at the blood-brain barrier. Nature Reviews Neuroscience. 2006; 7: 41-53.

43. Kniesel U, Wolburg H. Tight junctions of the blood-brain barrier. Cellular and molecular neurobiology. 2000; 20: 57-76.

44. Yao J, Zhang L, Zhou J, Liu H, Zhang Q. Efficient simultaneous tumor targeting delivery of all-trans retinoid acid and paclitaxel based on hyaluronic acid-based multifunctional nanocarrier. Molecular pharmaceutics. 2013; 10: 1080-91

45. Ying X, Wen H, Lu W-L, Du J, Guo J, Tian W, et al. Dual-targeting daunorubicin liposomes improve the therapeutic efficacy of brain glioma in animals. Journal of Controlled Release. 2010; 141: 183-92.

46. Chen Y, Jing Z, Luo C, Zhuang M, Xia J, Chen Z, et al. Vasculogenic mimicry-potential target for glioblastoma therapy: an in vitro and in vivo study. Medical Oncology. 2012; 29: 324-31.

47. Kirschmann DA, Seftor EA, Hardy KM, Seftor RE, Hendrix MJ. Molecular pathways: vasculogenic mimicry in tumor cells: diagnostic and therapeutic implications. Clinical Cancer Research. 2012; 18: 2726-32. 
48. Chen Y-S, Chen Z-P. Vasculogenic mimicry: a novel target for glioma therapy. Chinese journal of cancer. 2014; 33: 74-9.

49. Ricci-Vitiani L, Pallini R, Biffoni M, Todaro M, Invernici G, Cenci T, et al. Tumour vascularization via endothelial differentiation of glioblastoma stem-like cells. Nature. 2010; 468: 824-8.

50. Dean M, Fojo T, Bates S. Tumour stem cells and drug resistance. Nature Reviews Cancer. 2005; 5: 275-84.

51. Vidal S, Rodriguez-Bravo V, Galsky M, Cordon-Cardo C, Domingo-Domenech J. Targeting cancer stem cells to suppress acquired chemotherapy resistance. Oncogene. 2014; 33: 4451-63.

52. Gong $\mathrm{C}, \mathrm{Li} \mathrm{X}, \mathrm{Xu} \mathrm{L}$, Zhang $\mathrm{Y}-\mathrm{H}$. Target delivery of a gene into the brain using the RVG29-oligoarginine peptide. Biomaterials. 2012; 33: 3456-63.

53. Qin Y, Chen H, Yuan W, Kuai R, Zhang Q, Xie F, et al. Liposome formulated with TAT-modified cholesterol for enhancing the brain delivery. International journal of pharmaceutics. 2011; 419: 85-95.

54. Qin Y, Chen H, Zhang Q, Wang X, Yuan W, Kuai R, et al. Liposome formulated with TAT-modified cholesterol for improving brain delivery and therapeutic efficacy on brain glioma in animals. International journal of pharmaceutics. 2011; 420: 304-12.

55. Yan $\mathrm{H}$, Wang L, Wang J, Weng $\mathrm{X}$, Lei $\mathrm{H}$, Wang $\mathrm{X}$, et al. Two-order targeted brain tumor imaging by using an optical/paramagnetic nanoprobe across the blood brain barrier. ACS nano. 2011; 6: 410-20.

56. Barczyk M, Carracedo S, Gullberg D. Integrins. Cell and tissue research. 2010; 339: 269-80.

57. Kibria G, Hatakeyama H, Ohga N, Hida K, Harashima H. Dual-ligand modification of PEGylated liposomes shows better cell selectivity and efficient gene delivery. Journal of Controlled Release. 2011; 153: 141-8.

58. Sugahara K, Teesalu T, Ruoslahti E. Tumor-penetrating peptides. Frontiers in Oncology. 2013; 3: 1-8.

59. Itzhaki O, Greenberg E, Shalmon B, Kubi A, Treves AJ, Shapira-Frommer R, et al. Nicotinamide inhibits vasculogenic mimicry, an alternative vascularization pathway observed in highly aggressive melanoma. PloS one. 2013; 8: e57160.

60. Wang H, Sun W, Zhang W-Z, Ge C-Y, Zhang J-T, Liu Z-Y, et al. Inhibition of Tumor Vasculogenic Mimicry and Prolongation of Host Survival in Highly Aggressive Gallbladder Cancers by Norcantharidin via Blocking the Ephrin Type a Receptor 2/Focal Adhesion Kinase/Paxillin Signaling Pathway. PloS one. 2014; 9: e96982 